\title{
Benchmarking Case Study, Applying Sustainable -Eco - Building Assessment Method (SEBAM) in Greater Khartoum, Comparing with Global Systems
}

\author{
Hind Khogali ${ }^{1}$ \\ ${ }^{1}$ Architecture Department, College of Architecture Engineering and Digital Design, Dar Al Uloom University, \\ Saudi Arabia \\ Correspondence: Hind Khogali, Architecture Department, College of Architecture Engineering and Digital Design, \\ Dar Al Uloom University, Saudi Arabia. Tel: 996-61-1494-9123. E-mail: ahind@dau.edu.sa
}

Received: January 16, 2020

Accepted: May 12, 2020

Online Published: May 26, 2020

doi: $10.5539 /$ jsd.v13n3p33

URL: https://doi.org/10.5539/jsd.v13n3p33

\begin{abstract}
This sample was taken as benchmarking in (Abdelmoneim, H., 2019) which has got the higher points comparing with all the other samples studied in this research, is chosen for global assessment approach an excellent solution for the sustainable-eco-building assessment method (SEBAM).

This study aims is to present and analyses a benchmarking case study for sustainable eco-buildings in Greater Khartoum is the capital of Sudan, one of The greatest countries in north Africa.

The methodology is applying global assessment method to this case study, which is LEED, BREEAM, AGBC, ESTIDAMA and GSAS then compare the result with the local system came up of (Abdelmoneim, H., 2019), sustainable eco-building assessment method to evaluate residential buildings (SEBAM) to justify the results. The comparison is done in this research in the main categories and results. The outcomes show differences rather than similarities this will be discussed in the paper and come up by conclusion and recommendations.
\end{abstract}

Keywords: sustainable eco-building assessment method (SEBAM), LEED, BREEAM, AGBC, GSAS, ESTEDAMA, SEBAM.

\section{Introduction}

The location of the case study is in South East Khartoum city, the climate is a hot dry climate. This house was built in Geraif West Neighbourhood in Khartoum city; it was built in the late nineties. It attempted to demonstrate several features of significance to the designer. See figure 1 showing the location of the case study at Khartoum the capital of Sudan. 


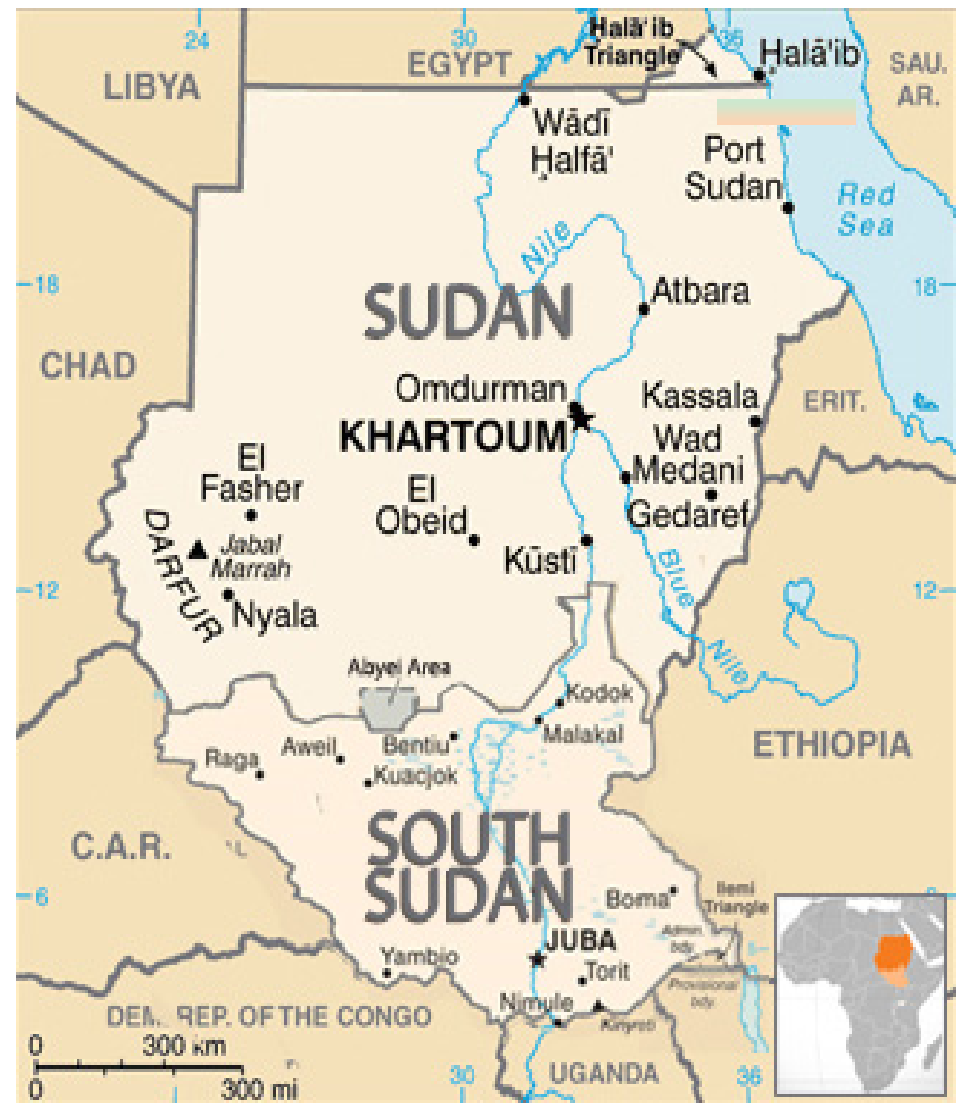

Map 1. The political map, 2020 (Washington DC, 2020)

\subsection{Climatic Conditions}

Khartoum's climate is characterised by its hot and dry nature. In addition, is characterised by intensive heat resulting from the blowing of dust storms (i.e., Haboobs) from the South East. This phenomenon, in fact, produces one of the most striking weather features experienced in the area.

\subsection{Temperature}

There are three well-marked seasons in the year. The cooler winter season covers the period mid-November to March, and the summer season covers the period April to October. The temperature range in winter is from a high of $29^{\circ} \mathrm{C}$ to a low of $17^{\circ} \mathrm{C}$, and in summer, the temperature range is from $40^{\circ} \mathrm{C}$ to $28^{\circ} \mathrm{C}$.

\subsection{Rainfall}

In winter, the precipitation is effectively zero. The rainy season starts from July until the end of August with average rainfall in the capital region ranging from North to South at $100 \mathrm{~mm}$ to $200 \mathrm{~mm}$. As per reports, Khartoum's highest annual rainfall was $420 \mathrm{~mm}$ in 1988. The chain of rain decreases markedly after midSeptember.

\subsection{Humidity}

The range of relative humidity in summer is $87 \%$ to $36 \%$, in winter it is $30 \%$, and in autumn, it is $40 \%$.

\subsection{Wind}

In summer, the wind direction is South East and South West. In winter, the wind direction is North East and North West. In June, during the summer season, the growing instability of weather can cause dust storms (also called Haboobs). However, robust Haboobs can occur in almost any month of the year. See

\subsection{Topography}

Khartoum land slopes gently at both flanks of the River Nile down towards the center (Jebel Marra, and Jebel Meidoob). Fine silt is deposited along the beds of the streams, and rich clays are generally abundant in the area. When we design a neighbourhood study of the topography, and the contour lines as well as the sea level features, 
it is very important to avoid flood areas and valleys.

\subsection{Vegetation}

The area is composed of land divided into three towns: Khartoum, Khartoum North, and Omdurman, and is 380 meters above sea level. The White Nile from the South and the Blue Nile from South East unite in Khartoum and provide a good source of water to the land. Another source is the rainwater in autumn, which is about $100 \mathrm{~mm}$. The distribution of the vegetation in Greater Khartoum is affected by the soil, the water sources, and the geology. There is little binding vegetation here, but going further south, the vegetation gradually changes from desert to semi-desert to Savannah with long grasses, and large trees near the river Nile.
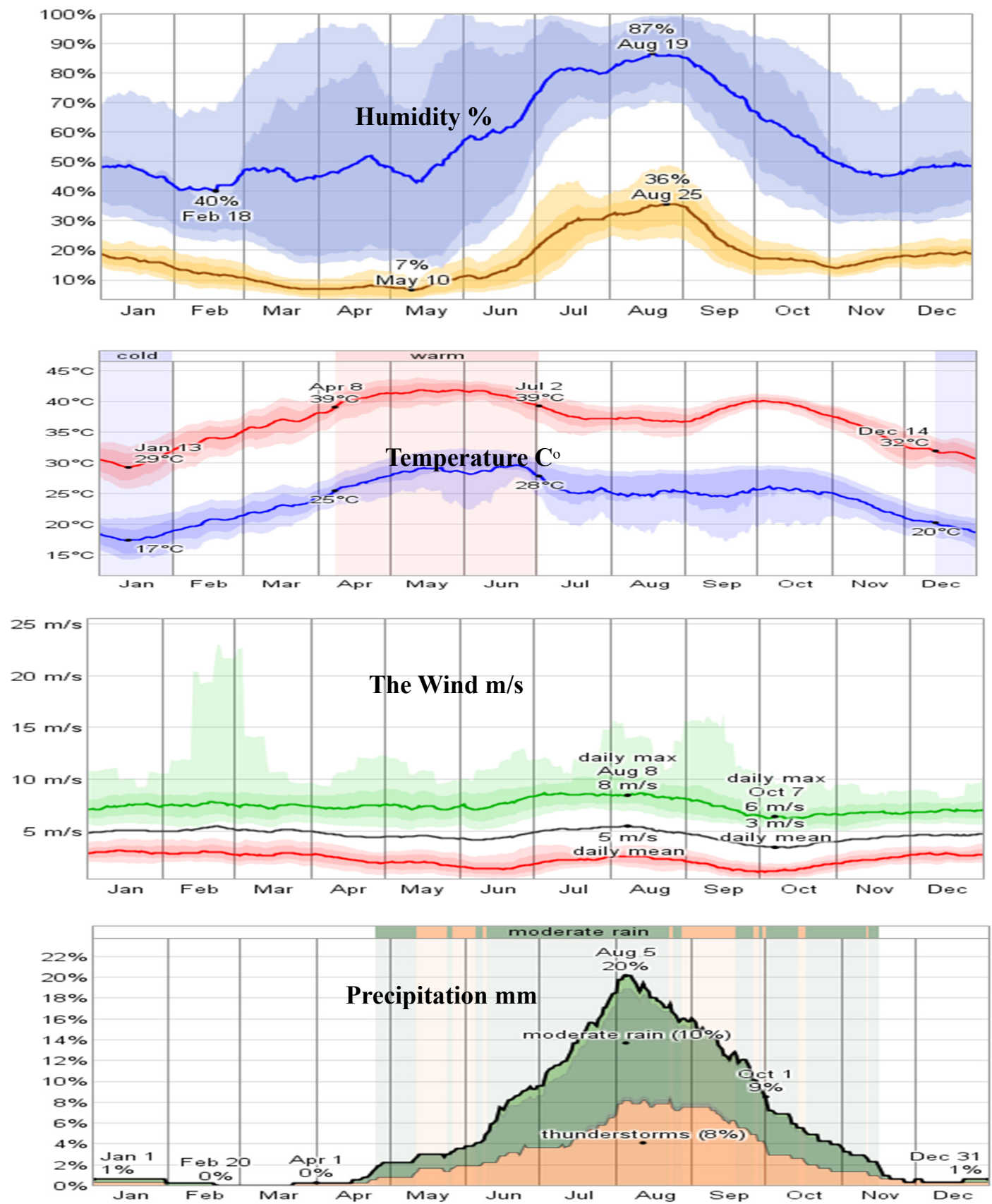

Figure a. Precipitation of metrological data in Greater Khartoum (www.weatherspeak.com, 2020)

\section{Literature Review}

Hassan Fathy conducted several works about sustainable design in the thirties and forties, and these efforts were later acknowledged in 1992. Since then an inclined trend was observed in the global community towards studying 
the relationship between building design and the surrounding environment. Specifically, a building should present a balanced and congruency with the surrounding environment in terms of social, economic and environmental aspects to achieve the sustainability goals and comfort for a human being. (Ibrahim, 1987).

The main principles of sustainable design, as presented in Table 1, are considered as the minimum standard to be followed for sustainable design.

The Leader in Energy and Environment (LEED, 2020) announced six main categories of sustainable design, which are the sustainable site, indoor environmental quality, energy, water, material,

and innovation. (GSAS, 2020) focuses on urban connectivity, Site, Energy, Water, Materials, Outdoor environment, Culture \& economic value. (BREEAM, 2020) BREEAM focuses on land use and land ecology, energy, water, material, health and wellbeing, transport, material, waste pollution and innovation. Royal Institute of British Architects' (RIBA), 2010) recommended land and ecology, community, health, materials, energy, and water as essential to sustainable design. Kubba (2010) and Fower (2006) Discussed these issues in "The Leader in Energy and Environment "LEED Practices.

Bromberek, (2009) discussed the principles of designing eco-resorts. The principles of eco-resort meet with the principles of the eco neighbourhood in site selection, landscaping, construction, energy management, water management, waste management and climatic performance. Barrows, (2009) presented the complete guidelines to green building. The guidelines for green buildings include constructions, planning phase, building materials, water, energy, lighting, roofs, floors, walls, windows, indoor air quality, outdoor, shades, green fencing, green lighting, green decking and green pool. Sassi, (2006) and Van, (2009) published a book in 1996, the title of its second part is "The Ecological Design Process". They discussed the principles of ecological design, which are: solutions grow from the place, ecological accounting informs design, design with nature, everyone is a designer, and make nature visible. (Su, 2016) published a paper in IECC, International conference in Environmental and Climatic Change Comparison of field measurement CFD simulation is implemented to recreate thermal conditions of two buildings in both seasons. To evaluate the field measurement results in natural ventilation effect at the atrium, with the air velocity. (Alwetaishi, 2018) published a paper in IECC

International conference in Environmental and Climatic Change in France. The paper concentrated in the passive solutions and stated that it is one way to ensure low building energy, the researcher applied Thermal Analysis Simulation (TAS) will be utilized which is powered by Environmental Design process. (UN-HABITAT, 2016) the report presented at the 3rd International Conference for housing and sustainable planning. The report covered most of the points of UN sustainable development goals about Sudan. (Zuhal, November 2018) published paper in International conference and the built environment in London Zuhal discussed the low coast housing in Greater Khartoum, in New Deims, El Shabyia, Al Iskan the Project, Elthora hara and compare in size, area, design type , and house type. (Zuhal, 2014) published paper in The Opportunities and Challenges for Sustainabilty in Old Neighbourhoods)- A Case Study of Aburoof Neighbourhood in Sudan showing the opportunities of the sustainable community. Khalil (2014) published paper about PhD research in sustainable tools in Khartoum Projects. Khalil (2014) used LEED-ND, BREEAM, and CASBEE systems for his study and discussed that his study reflects the social and economic needs of Greater Khartoum. He furthermore suggested to include energy, natural system, materials, society, services, business and creative design in evaluating sustainable projects in Greater Khartoum. Abdelmoneim, H., (2016) published a paper in JSD about comparison in four global systems showing and analysing the main categories of the global systems with their weighings. In addition Abdelmoneim, H., (2016) Published paper in JSD about the local sustainable-eco-building SEBAM come out of $\mathrm{PhD}$ research to be applied in Greater Khartoum in Sudan.

\subsection{Definition of Eco Buildings}

Specifically, eco-building concentrates on the passive solutions, which uses natural solutions in design without mechanical means, such as ventilation, building orientation, natural light, improve air movement, use of local building material and the use of natural resources in energy, water, and material. All these issues will be discussed in this chapter. The meaning of eco-homes can be derived from the term 'eco', which finds its origin in the Greek root 'Oikos', meaning 'household'. The Greek root has two meanings: the sense of 'ecological' relationships between organisms in nature, and 'economics' relationships with the use of 'resources. Additionally, the idea also pertains to the use of new knowledge, materials and renewable technologies to create buildings and refers to the new vernacular aimed at minimizing the adverse environmental impacts of the buildings (Hyde, 2008). Diverse environmental impacts can be measured using new methodologies for counting the environmental costs of buildings, the first eco House in the UK. 


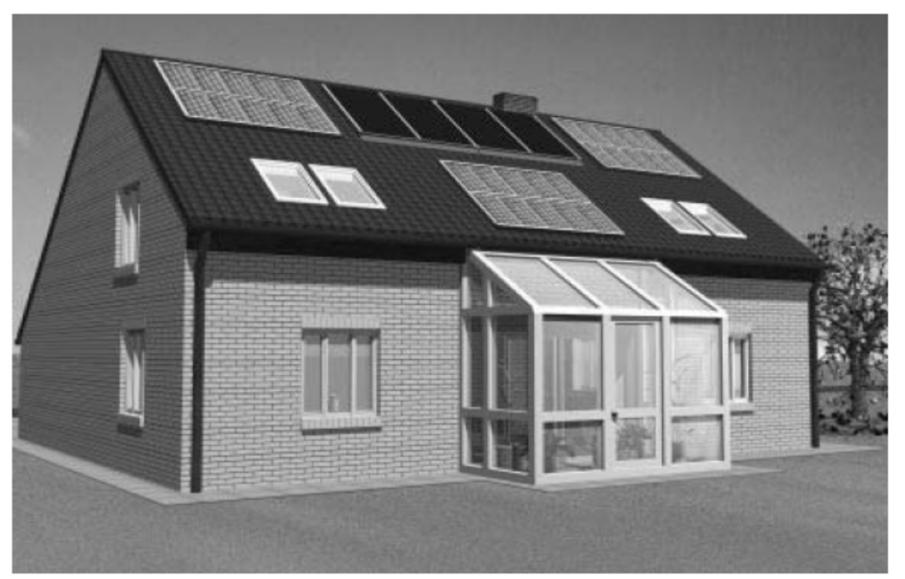

Figure b. (Roaf, 2013). The first eco -house in the UK in 2013 showing the use of passive solutions with the solar energy system

\section{Objectives}

3.1 To find Benchmarking case study in sustainable-eco-building in Greater Khartoum.

3.2 To compare global solutions for sustainable eco- buildings with (SEBAM) in Greater Khartoum was discussed and published (Abdelmoneim, H. 2020).

3.3 To find out the applicable solutions from the global systems (Abdelmoneim, H., 2019).

3.4 To find out an applicable solution from the local system applied the SEBAM (Abdelmoneim, H., 2019) and (Abdelmoneim, H., 2020) contain eight main categories see Table 1, Figure 1.

\section{Introduction to the Case Study}

In this case, the keywords were environment, traditions and modernity. Great consideration was hence given to orientation and shading and to the passive solution.

The location of the case study is in Khartoum middle, Gerif west. The plot area is $400 \mathrm{~m}^{2}$, the house has a square plan, in the ground floor the main reception, kitchen, office room, in the first floor the bedrooms and family hall. The climate is detailed in 1.1 page 2 .

Natural ventilation was made easier by the intrinsically narrow plan and the open multi-level interior. A windcatcher further accentuated this and underground brick ducts for supplying cool filtered air. Small high-level openings siphoned the hot air and enhanced convectional currents. The incorporation of plants in the interior was combined with a water sprinkling system for irrigation and climate modification. Solar energy provided the backup supply for lighting and low-demand appliances as well as Water: It is from the National Grid; water efficiency is $70 \%$; which indicates a shortage of water supply. Drainage system: septic tank and well. Energy: supplied from the National Grid, energy is generated through hydropower. The structure is a composite reinforcement concrete. Frame and brick load-bearing walls system. The frame constitutes a stiff core holding brick vaults and combating the resulting lateral forces. The area framed by the RC skeleton receded upwards from the ground level to the first level, leaving the third level for loadbearing walls. Perpendicular vaults acting as buttresses framing openings and casting shadows further assist this. The interior is softly rendered and made very simple and open. It accommodates artwork, feature panels and sometimes purposely designed furniture. 


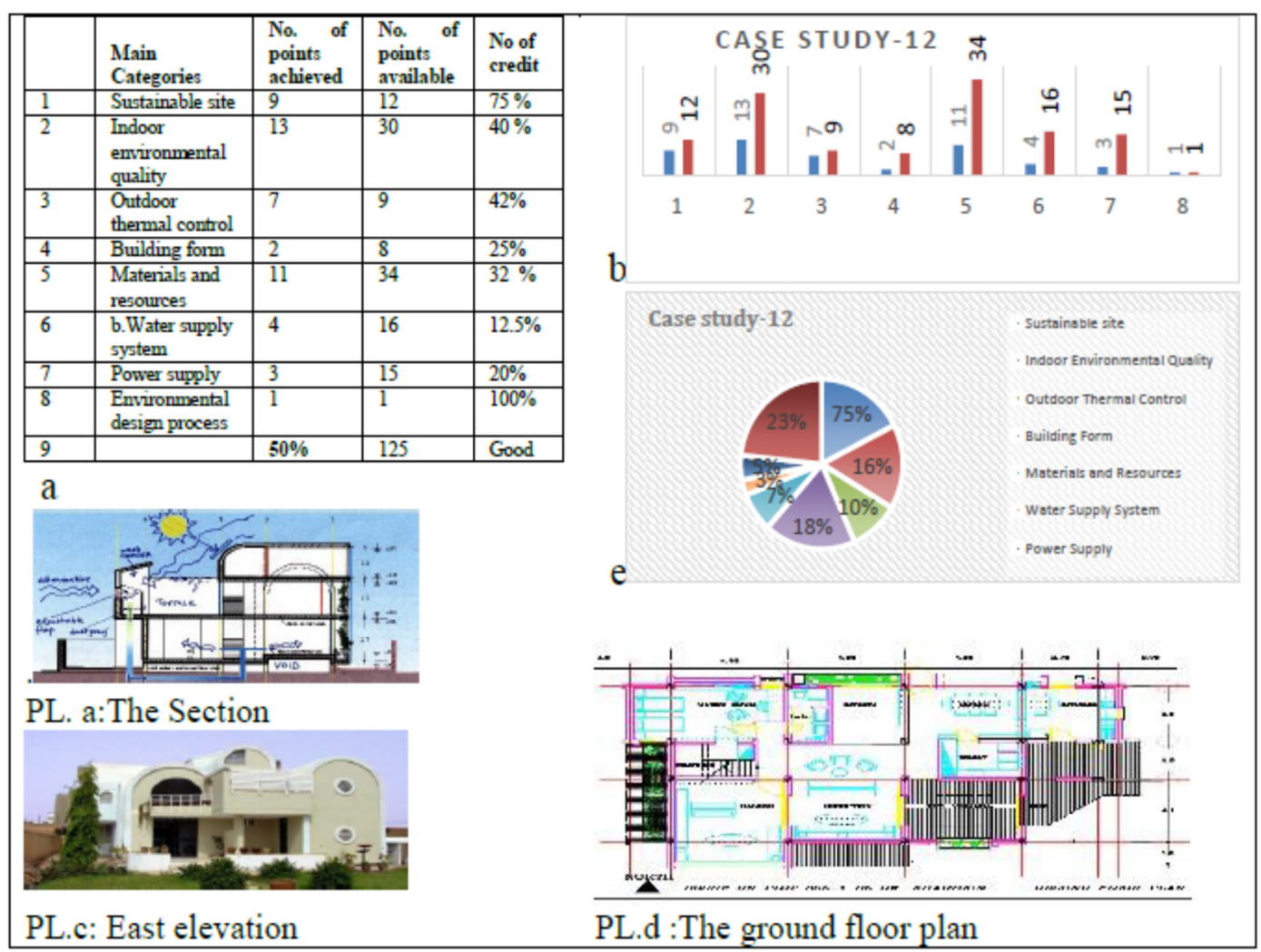

Figure 1. Benchmarking case study from Greater Khartoum

Source: (Abdelmoneim, H., 2019)

\section{The Methodology}

The methodology is applying global assessment method to this case study, which is LEED, BREEAM, AGBC, ESTIDAMA and GSAS then comparing the results with the local system sustainable-eco-building assessment method to evaluate residential buildings (SEBAM) to justify the results.

The global systems were well known and detailed in (Abdelmoneim, H., 2016) and SEBAM were detailed in (Abdelmoneim, H., 2020).

\section{Results and Findings}

6.1 The Local System: Sustainable-Eco-Building Assessment Method (SEBAM)

Table 1. The Local system SEBAM, applied to the case study, results

\begin{tabular}{lcccc}
\hline & Main Categories & No. of points achieved & No. of points available & No of credit \\
\hline 1 & Sustainable site & 9 & 12 & $75 \%$ \\
2 & Indoor environmental quality & 13 & 30 & $40 \%$ \\
3 & Outdoor thermal control & 7 & 9 & $42 \%$ \\
4 & Building form & 2 & 8 & $25 \%$ \\
5 & Materials and resources & 11 & 34 & $32 \%$ \\
6 & b.Water supply system & 4 & 16 & $12.5 \%$ \\
7 & Power supply & 3 & 15 & $20 \%$ \\
8 & Environmental design process & 1 & 1 & $100 \%$ \\
9 & Total & $\mathbf{5 0} \%$ & 125 & Good \\
\hline
\end{tabular}

Source: The global systems were well known and detailed in (Abdelmoneim, H., 2016) and SEBAM were detailed 
in (Abdelmoneim, H., 2020).

6.2 Green Star Rating System IN AUSTRALIA

Table 2.The result by the Green Star Rating System

\begin{tabular}{lccc}
\hline Credit & Number of points Achieved & Number of points available & $\mathbf{\%}$ \\
\hline Management & 7 & 14 & $50 \%$ \\
Indoor environment quality & 17 & 17 & $100 \%$ \\
Energy & 7 & 22 & $31 \%$ \\
Transport & 8 & 10 & $80 \%$ \\
Water & 8 & 12 & $66.66 \%$ \\
Materials & 4 & 14 & $28.5 \%$ \\
Land use and ecology & 3 & 6 & $50 \%$ \\
Emissions & 1 & 5 & $20 \%$ \\
Innovation & 3 & 10 & $30 \%$ \\
\hline Total & 50 points & 110 & \\
& 4 star & & \\
\hline
\end{tabular}

Source: Designed by the researcher.

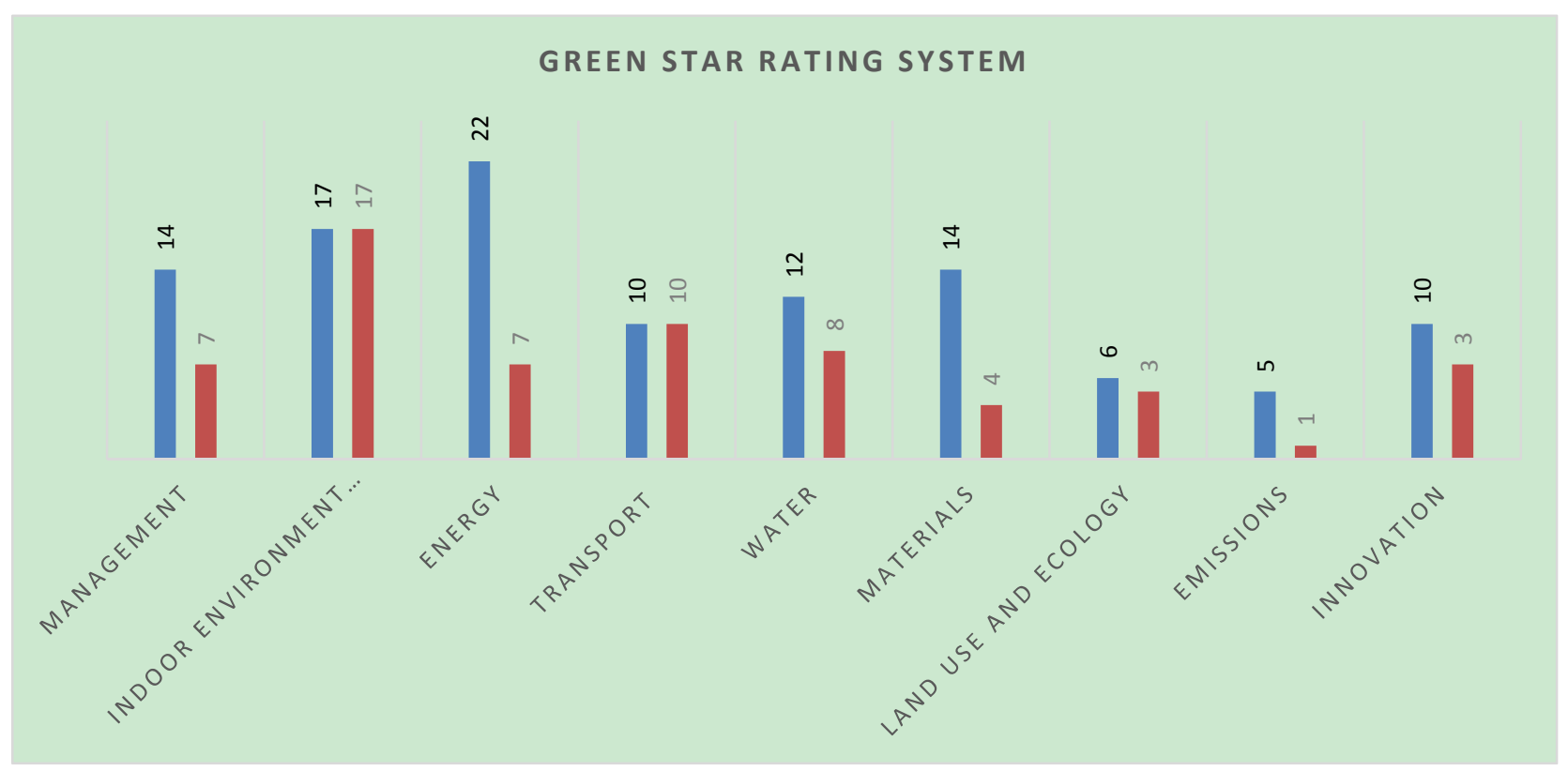

Fig. 2. Shows the Green Star Rating System results for one case study

Source: Adapted by the researcher. 


\subsection{The BREEAM Rating System in the UK}

Table 3 . The result by BREEAM rating system in the UK

\begin{tabular}{lccc}
\hline Issue name & Achieved & Credit available & $\%$ \\
\hline Land use and land ecology & 2 & 10 & $20 \%$ \\
Energy & 19 & 31 & $61 \%$ \\
Water & 4 & 9 & $44.4 \%$ \\
Material & 6 & 14 & $42.8 \%$ \\
Health and wellbeing & 4 & 22 & $18.1 \%$ \\
Transport & 2 & 12 & $16.6 \%$ \\
Materials & 8 & 14 & $57.1 \%$ \\
Waste & 6 & 9 & $66.66 \%$ \\
pollution & 2 & 13 & $15.3 \%$ \\
Innovation & 3 & 10 & $30 \%$ \\
\hline Total & 56 (very good) & 144 & \\
\hline
\end{tabular}

Source: Adapted by the researcher.

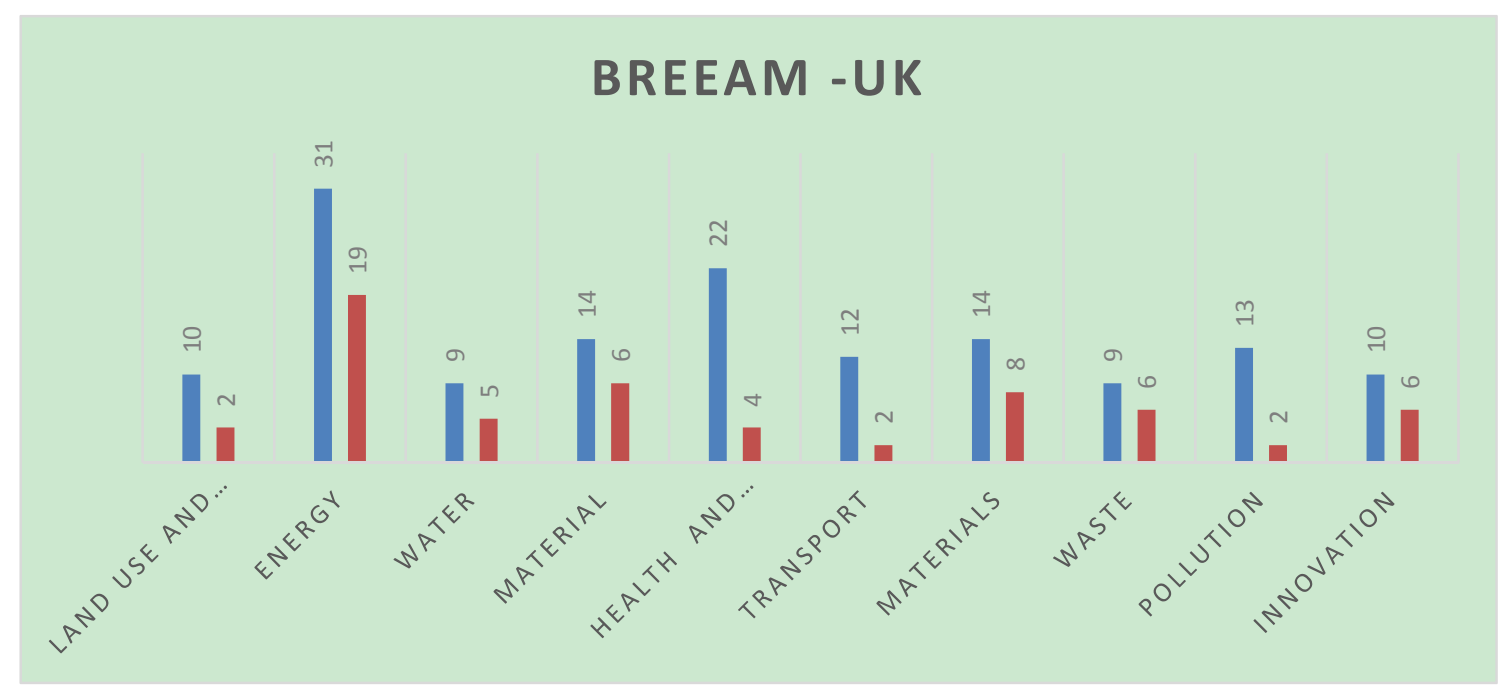

Fig. 3. Shows the results of the BREEAM applied for one case study

Source: Adapted by the researcher

6.4 The Leader in Energy and Environment Development (LEED)

Table 4 . The result by LEED V4 rating system

\begin{tabular}{lccc}
\hline Category & Point achieved & Point available & $\%$ \\
\hline Location and Transportation & 10 & 15 & $66 \%$ \\
Sustainable site & 6 & 10 & $62 \%$ \\
Water efficiency & 10 & 12 & $83 \%$ \\
Energy \& atmosphere & 12 & 38 & $31.3 \%$ \\
Material \& resources & 3 & 8 & $37 \%$ \\
Indoor environment & 4 & 17 & $23 \%$ \\
innovation & 4 & 6 & $66 \%$ \\
Regional priority & 2 & 4 & $50 \%$ \\
\hline Total & $51 \%$ (silver) & 110 &
\end{tabular}

Source: Adapted by the researcher. 


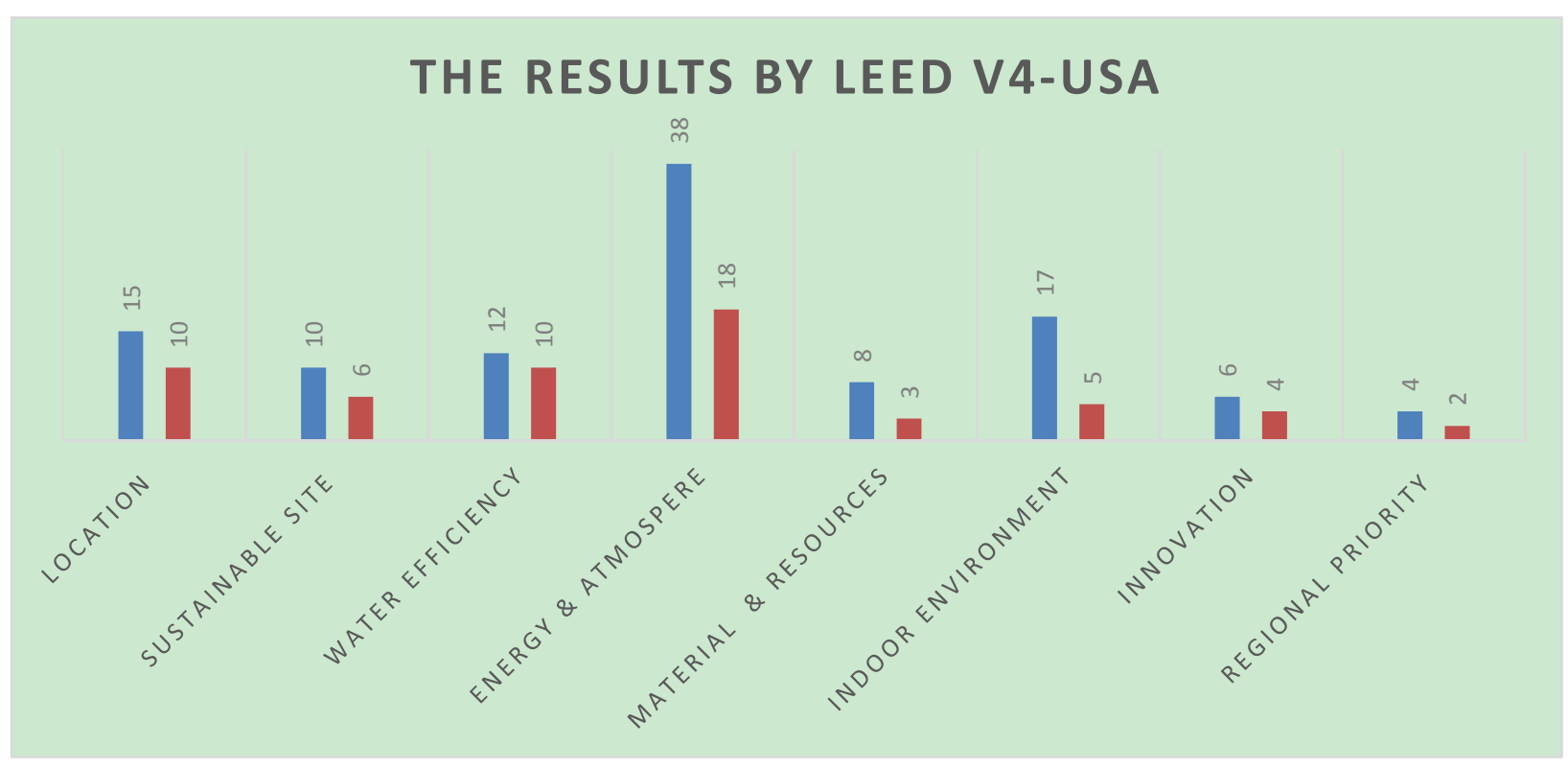

Fig. 4. Shows the results LEED V4 applied for one case study

Source: Adapted by the researcher.

\subsection{Estidama Building Rating System}

Table 5. The result by ESTIDAMA building rating system

\begin{tabular}{lccc}
\hline Credit & Achieved points & Maximum credit points available & $\%$ \\
\hline Integrated development process & 5 & 13 & $38 \%$ \\
Natural system & 2 & 12 & $16.6 \%$ \\
Livable building: outdoors & 8 & 14 & $57.14 \%$ \\
Livable Building: indoor & 17 & 23 & $73.9 \%$ \\
Precious water & 8 & 43 & $18.6 \%$ \\
Resourceful energy & 9 & 44 & $20.4 \%$ \\
material & 14 & 28 & $50 \%$ \\
Innovation practice & 2 & 3 & $66.6 \%$ \\
\hline Total & 65 & 180 & \\
& $(2$ pearl $)$ & & \\
\hline
\end{tabular}

Source: Adapted by the researcher. 


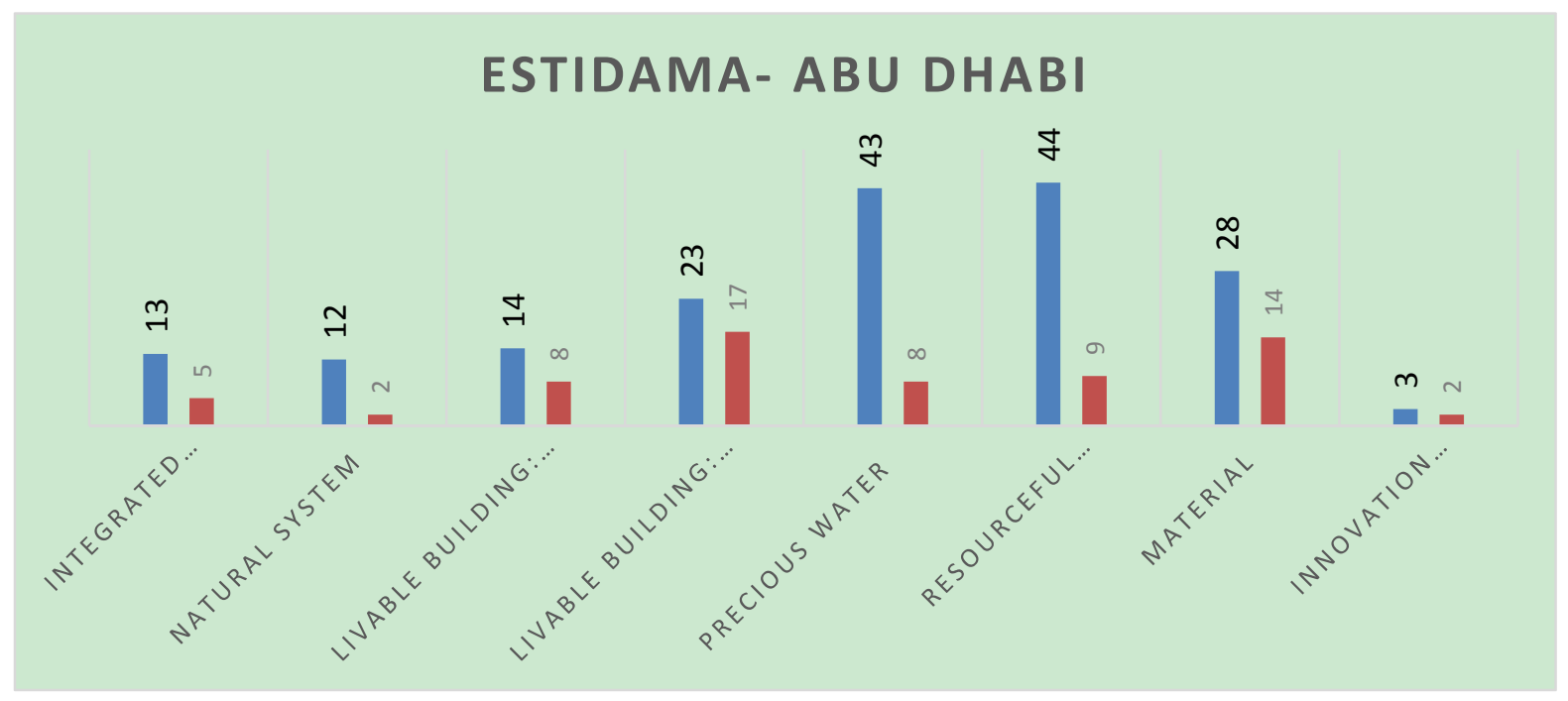

Fig. 5. Shows the results of ESTIDAMA applied for one case study

Source: Adapted by the researcher.

6.6 Global Sustainability Assessment System (GSAS)

Table 6. The result by GSAS

\begin{tabular}{llccc}
\hline & Category & Achieved weight & Weighing available & $\%$ \\
\hline UC & Urban connectivity & 7 & 7 & $100 \%$ \\
S & Site & 2.74 & 15 & $18 \%$ \\
E & Energy & 6.87 & 24 & 28.6 \\
W & Water & 6 & 16 & 37.5 \\
M & Materials & 5.7 & 12 & 47.5 \\
IE & Outdoor environment & 4.03 & 16 & $25 \%$ \\
CE & Culture \& economic value & 3.12 & 7 & $44.5 \%$ \\
MO & Management and operation & 1.2 & 8 & $15 \%$ \\
\hline & Total & 36.66 & 105 & \\
& & 2 stars & & \\
\hline
\end{tabular}

Source: Adapted by the researcher.

\section{GSAS-QATAR}

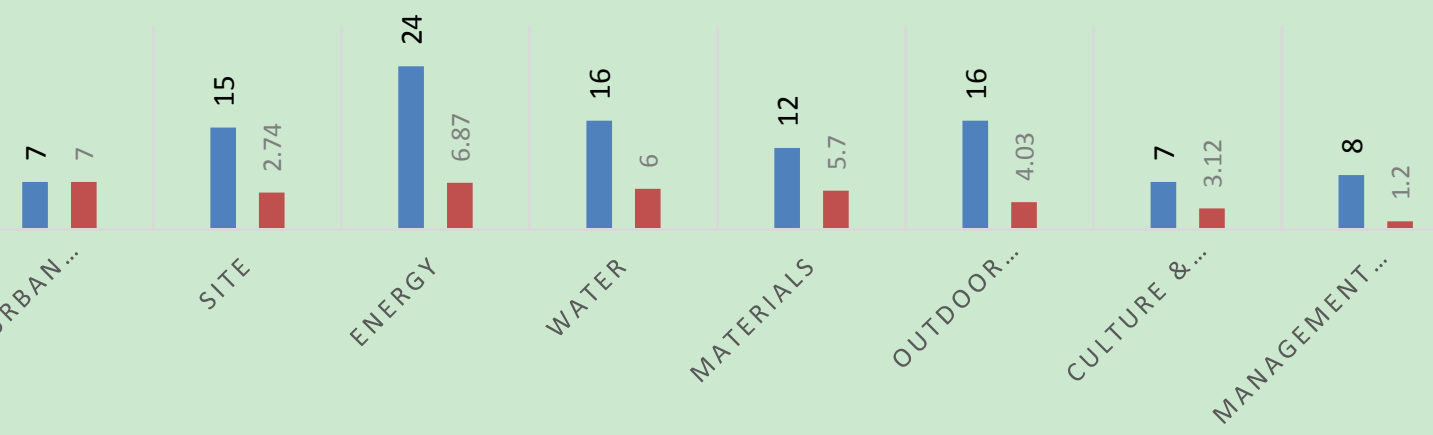

Fig. 6. Shows the results of GSAS applied for one case study

Source: Adapted by the researcher. 


\section{Benchmarking Genral Results by Applying Global systems compared by local system SEBAM}

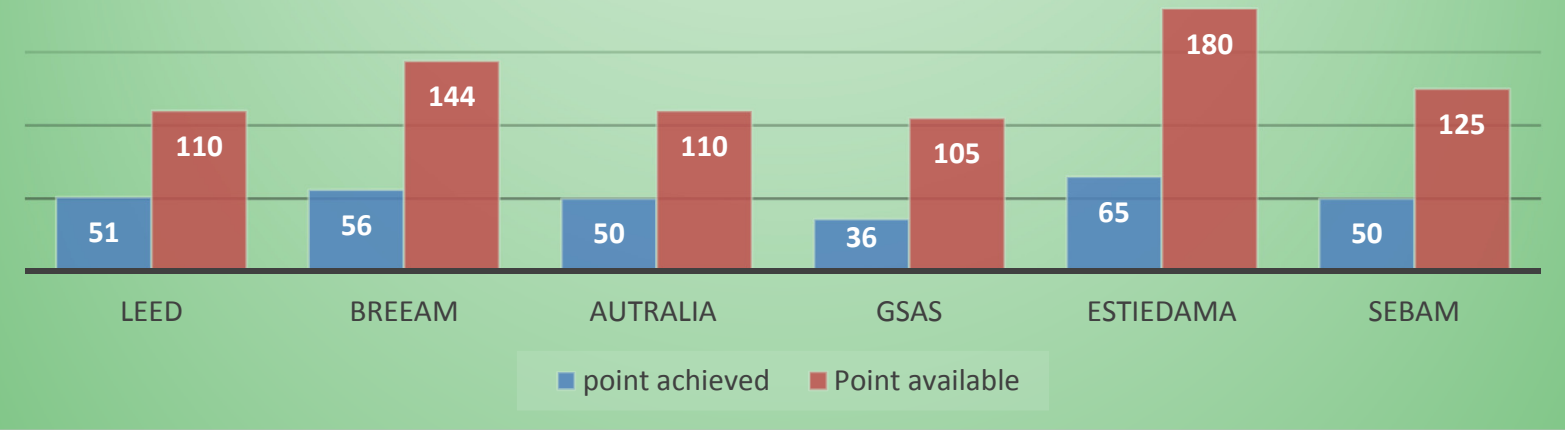

Fig. 7. Benchmarking general results by applying global systems compared by local system SEBAM

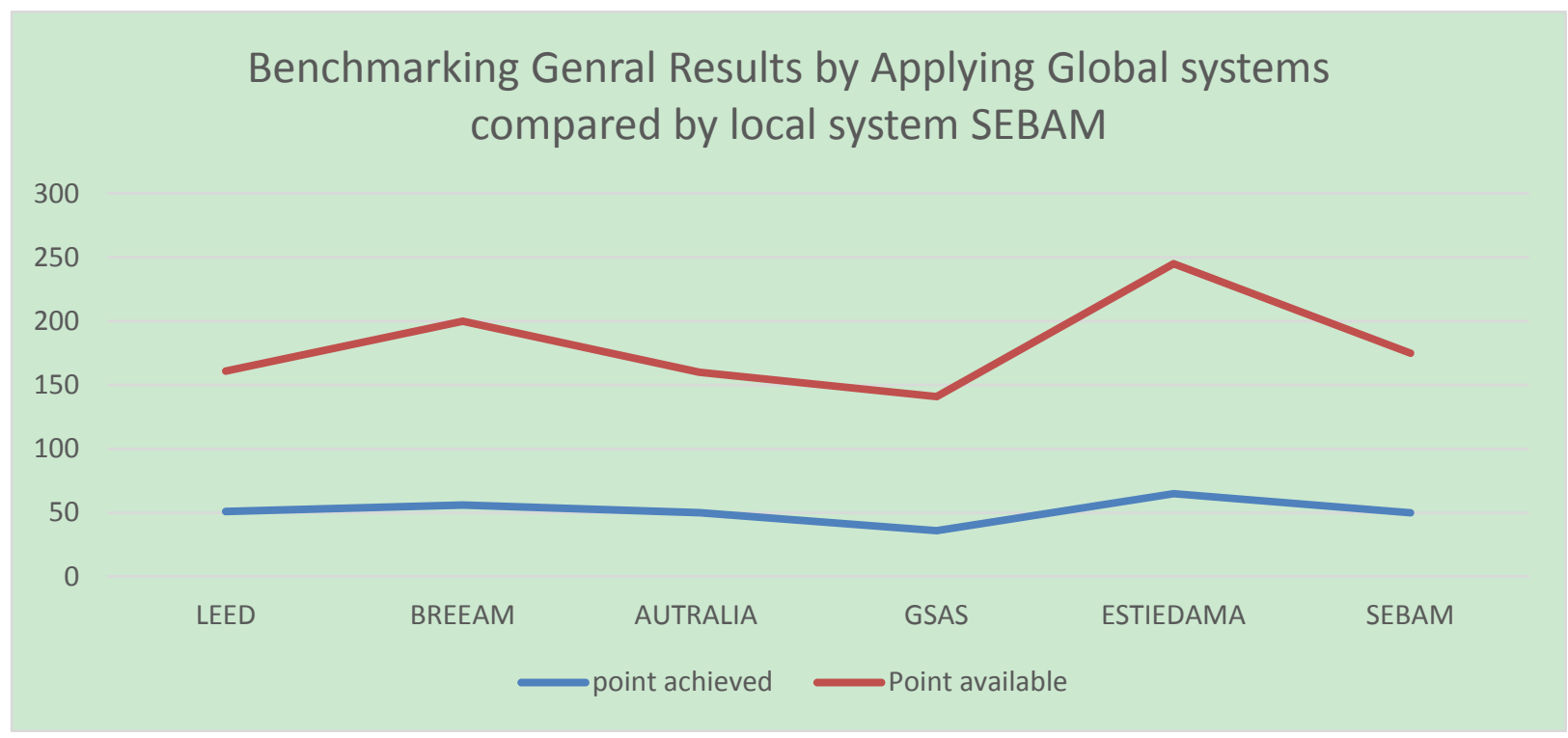

Fig. 8. Benchmarking case study general results by applying global systems compared by local system SEBAM

Note that the results by the global systems and the local system SEBAM are nearly to each other there is some differences in details and weight. Figure 1, Table 1 showing the results of SEBAM it is 50\%, while Figure 2, Table 2 showing the result of Australia GB it is $50 \%$, in addition to that Table 3, Figure 3 showing the result of BREEAM it is 51 points, also Figure 4, Table 4 showing the results of LEED it is 51 points, Figure 5, Table 5showing the result of ESTEDAMA it is 65 points ( 2 pearls) finally; Table 6, Figure 6 showing the result of GSAS it is 36 (2 stars).Figure 7 and figure 8 concluded the results.

Although the results are near to each other, but there are still differences in the details and weighing according to the details because of the local environment and social and economic differences.

\section{Discussion of the Results}

The case study was analyzed first by the research method of assessment, the applied the solutions found are the good accessibility, parking with cover shed, concrete structure, bricks, glass and aluminium. Vaults over the bedrooms, double-height with a green plant. Large garden with shrubs and trees. Solar panel. Recycled greywater. A windcatcher further accentuated this and underground brick ducts for supplying cool filtered air. Small high- 
level openings siphoned the hot air and enhanced convectional currents.

Although, this sample was analyzed by the five global assessment methods, which are: GBCA, BREEAM, LEED, ESTIDAMA AND GSAS, SEBAB sustainable building assessment method in chapter six to find out the global challenges in applying the sustainable assessment methods in Greater Khartoum.

\subsection{The Site and Management}

The applied solutions such as GBCA: building information committed to performance, metering and monitoring, construction environmental management, BREEAM: Site selection, the ecological value, in addition, LEED added building exterior and hard cape management plan, erosion control, alternative transportation, heat island effect and lighting control. In addition, ESTIDAMA added improved outdoor thermal comfort, private outdoor space, public transportation, parking space, lighting control, in addition to that, GSAS added transportation load, proximity to the existing district, solid waste management. In spite of the fact that the not applied solutions such as AGBC: green star certified professional, commissioning and tuning, adaptation and resilience, but BREEAM is not Appling minimizing the impact on existing site ecology, enhancing site ecology, and long term has an impact on biodiversity. However, LEED is not Appling to LEED - certified design, management plan, site development, stormwater control despite, ESTIDAMA is not Appling urban system assessment outdoor thermal strategy, rated communities, accessible community facilities, active urban environment, bicycle facilities and travel plan. GSAS: None.

\subsection{Water Facilities}

The applied solutions such as GBCA: Portable water and BREEAM added water consumption, water monitoring, and water-efficient equipment, also LEED applied plumbing factor, water-efficient, landscape, also, ESTIDAMA added water use reduction, and GSAS applied water consumption. However, The not applied solutions such as GBCA: partial, but BREEAM not applied water leak detection, however, LEED not applied indoor plumping efficiency, water performance measurement and cooling tower, on the other hand, ESTIDAMA is not applied interior water use reduction, exterior water monitoring, improve interior water reduction, exterior water use reduction, and water monitoring and stormwater.

GSAS: partial

\subsection{Energy}

The applied solutions such as GBCA: Greenhouse Gas Emissions, peak electricity reduction, and BREEAM: reduction of energy use, energy monitoring, external lighting, low carbon design, energy-efficient transportation system, also LEED: energy efficiency, energy metering in addition to that, ESTEDAMA: renewable energy, and GSAS: energy delivery performance. In spite of the fact that the

not Applied Solutions such as GBCA: all solution, but BREEAM: energy efficient cold storage, energy- efficient transportation system, however, LEED: energy efficient best practice, energy performance, fundamental refrigerant, exiting building commissioning, building automation system emission reduction reporting although.

ESTIDAMA: minimum energy performance, energy monitoring, and ozone impact improve energy performance, cool building strategies, vertical transportation, peak load reduction but, GSAS: fossil fuel conservation, $\mathrm{CO}_{2}$ emissions, $\mathrm{NO}_{\mathrm{x}}, \mathrm{So}_{\mathrm{x}}$ matter.

\subsection{Material}

The applied Solutions such as GBCA applied responsible building materials, construction and demolition waste and, BREEAM applied responsible sourcing of materials, insulation, design for durability, material efficiency, hard landscaping and boundary protection in addition, LEED added sustainable purchasing, sustainable furniture, sustainable food. In addition, ESTIDAMA added non-polluting material, design for flexibility, modular flooring system, design for durability, recycling materials, waste management, and GSAS added regional material, responsible sourcing materials, recycled materials. However, The not applied solution such as GBCA: life cycle impact, sustainable products, but BREAM not added Life cycle impact on the other hand LEED not added sustainable policy, solid waste policy, reduction mercury lamps, ESTIDAMA not added design material reduction, design for disassembly, building reuse, material reuse, regional material, rapidly renewable material, reused certified timber, and improve operation waste management, organic waste management. GSAS not applied material reuse and LCA.

\subsection{Indoor Environment}

The applied solutions such as GBCA applied indoor air quality, acoustic comfort, lighting comfort, visual comfort, indoor pollutants, and thermal comfort. BREEAM applied None, LEED: Best management practice, control 
lighting, daylight and view, sustainable cleaning equipment, chemical control in addition to that, ESTIDAMA applied ventilation quality, materials emissions, indoor air quality, thermal zone, views, daylight, noise control, secure environment. GSAS: has no indoor environment category.

\section{Not applied solutions such as GBCA: None}

BREEAM: applied all, LEED did not apply environmental tobacco control, green cleaning, occupant comfort, ESTIDAMA not applied thermal comfort control, thermal comfort modelling and, GSAS: applied all.

Addition of New categories such as GBCA: emissions, innovations, but BREEAM added health wellbeing, transportation, waste, pollution, innovation, on the other hand, LEED added innovation, regional priority, but ESTIDAMA added integrated design process, natural system, innovation. On the other hand, GSAS added urban connectivity, culture value, management and operation.

There are fixed 5 main categories between these global assessment methods which are: sustainable site, indoor environment quality, building material, water efficiency, energy efficiency, on the other hand, each system added additional categories like GBCA added management and ecological category and emission. ESTIDAMA added integrated development process, livable community and innovation. LEED added innovation and regional priority. BREEAM added health wellbeing, transport, waste, pollution and innovation. GSAS added urban connectivity, culture value and management. Because of these additional categories and different sub-issues, the result was varying from system to another: The conclusion from the analysis of "one case study" by the global systems are different variation in the result: GBCA (63, five STAR), BREEAM (68, very good), LEED (60, gold). GSAS (5 stars), ESTIDAMA (3 pearls). For all not applied solutions, the reasons are educational and economic reasons. Solutions need to be educated like green star certified professional, LEED-certified design, by having workshops or continuous educations courses in specific assessment methods. Solutions not applied for its highly expensive solutions like energy -efficient transportation system. It is very important to study their local environmental, special, technological conditions in the local environment in Greater Khartoum and apply economical solutions suitable to local environmental, social and economic value. The research method of assessment studied the conditions of Greater Khartoum in chapter three and added three categories suitable to local environmental social and economic conditions, detailed by the passive solutions can be applied in our houses, which are, building form, outdoor environment and sustainable design process to add educational value.

\section{Conclusions}

The conclusion from the analysis of "one case study" by the global systems are different variation in the result: The proposed research method of assessment SEBAM (50 points), GBCA (63, 5 stars), BREEAM (66, very good), LEED (58, silver). GSAS ( 2 stars), ESTIDAMA ( 2 pearls) because of the difference in the main categories and sub- issues to achieve their local goals in the environment, culture, social and economic value. On the followings, the researcher discusses the result to find out the applicable solutions to Greater Khartoum and not applicable solutions to highlight them as global challenges.

\subsection{Site and Management}

The research come-out of the need to apply solutions such as GBCA: building information, commitment to performance, metering and monitoring, construction environmental management.

BREEAM: site selection, ecological value. LEED: building exterior and hard cape management plan, erosion control, alternative transportation, heat island effect and lighting control. ESTIDAMA: improved outdoor thermal comfort, private outdoor space, public transportation, parking space, lighting control. GSAS: transportation load, proximity to the existing district, solid waste management.

\subsection{Water Facilities}

The research Applied solutions in water facilities such as GBCA: Portable water. BREEAM: water consumption, monitoring and efficient equipment. LEED: Plumbing factor, water- efficient landscape. ESTIDAMA: water use reduction. GSAS: water consumption.

\subsection{Energy}

The research applied solutions in energy efficiency such as GBCA: Greenhouse gas emissions, peak electricity reduction. BREEAM: Reduction of energy use, energy monitoring, external lighting, low carbon design, energy efficient transportation system. LEED: energy-efficiency, energy metering. ESTEDAMA: renewable energy. GSAS: energy delivery performance. 


\subsection{Material}

The research applied solutions in the material such as GBCA: Responsible building materials, construction and demolition waste. BREEAM: Responsible sourcing of materials, insulation, design for durability, material efficiency, hard landscaping and boundary protection. LEED: sustainable purchasing, sustainable furniture, sustainable food. ESTIDAMA: Non-polluting material, design for flexibility, modular flooring system, design for durability, recycling materials, waste management. GSAS: regional material, responsible sourcing materials, recycled materials.

\subsection{Indoor Environment}

The research Applied solutions an indoor environment such as GBCA: indoor air quality, acoustic comfort, lighting comfort, visual comfort, indoor pollutants, thermal comfort. BREEAM: None. LEED: Best management practice, control lighting, daylight and view, sustainable cleaning equipment, chemical control. ESTIDAMA: ventilation quality, materials emissions, indoor air quality, thermal zone, views, daylight, noise control, secure environment. GSAS: None

New categories added by the global systems

GBCA: emissions, innovations. BREEAM: health wellbeing, transportation, waste, pollution, innovation. LEED: Innovation, the regional priority. ESTIDAMA: integrated design process, natural system, innovation. GSAS: urban connectivity, culture value, management and operation

There are fixed 5 main categories between these global assessment methods which are: sustainable site, indoor environment quality, building material, water efficiency, energy efficiency, on the other hand, each system added additional categories like GBCA added management and ecological category and emission. ESTIDAMA added integrated development process, livable community and innovation. LEED added innovation and regional priority. BREEAM added health wellbeing, transport, waste, pollution and innovation. GSAS added urban connectivity, culture value and management because of these additional categories and different sub-issues. The result was varying from system to another: The conclusion from the analysis of "one the case study" by the global systems are different variation in the result: GBCA (63, five STAR), BREEAM (68, very good), LEED (60, gold). GSAS (5 stars), ESTIDAMA (3 pearls).

For all not applied solutions, the reasons are educational and economic. Solutions need to be carefully selected; like green star certified professional, LEED-certified design, by having workshops or continuous educational courses in specific assessment methods. Solutions are not applied for its highly expensive solutions; like energyefficient transportation system. It is very important to study our local environmental, special, technological conditions in the local environment in Greater Khartoum and apply economical solutions that are suitable to the local environmental, social and economic value. The research method of assessment studied the conditions of Greater Khartoum in chapter three and added three categories suitable to local environmental social and economic conditions, detailed by the passive solutions can be applied in their houses, which are, building forms, outdoor environment and sustainable design process to add educational value.

\section{Recommendations}

The case study was analyzed by the proposed research method of assessment (SEBAM) and by the five global assessment methods, which are GBCA, BREEAM, LEED, ESTIDAMA, GSAS to find out the global challenges in applying the sustainable assessment methods in Greater Khartoum.

\subsection{Site and Management}

The research recommends keeping and increasing their applied solutions in the sustainable site like:

Building information, committed performance, metering and monitoring, construction environmental management, site selection, ecological value, building exterior and hard cape management plan, erosion control, alternative transportation, heat island effect and lighting control., improved outdoor thermal comfort, private outdoor space, public transportation, parking space, lighting control, transportation load, proximity to existing district, solid waste management.

\section{The research recommends adopting such solutions as:}

green star certified professional, commissioning and tuning, adaptation and resilience, minimizing impact on existing site ecology, enhancing site ecology, long term impact on biodiversity, LEED-certified design, management plan, site development, stormwater control, urban system assessment outdoor thermal strategy, rated communities, accessible community facilities, active urban environment, bicycle facilities and travel plan. 


\subsection{Water Facilities}

The research recommends keeping and increasing our applied solutions in water efficiency like:

Portable water, water consumption, water monitoring, water-efficient equipment, plumbing factor, water efficient landscape, water use reduction and water consumption.

The research recommends adopting such solutions as:

Water leaking detection, indoor plumping efficiency, water performance measurement and cooling tower, Minimum interior water use reduction, exterior water monitoring, improve interior water reduction, exterior water use reduction, and water monitoring and stormwater.

\subsection{Energy}

The research recommends keeping and increasing the applied solutions in energy such as Greenhouse Gas Emissions, peak electricity reduction, reduction of energy use, energy monitoring, external lighting, low carbon design, energy efficient transportation system, energy-efficiency, energy metering, renewable energy and energy delivery performance

The research recommends adopting solutions such as:

Energy-efficient cold storage, energy efficient transportation system,

Energy-efficient best practice, energy performance, fundamental refrigerant, exiting building commissioning, building automation system emission reduction reporting, minimum energy performance, energy monitoring, ozone impact, improve energy performance, cool building strategies, vertical transportation, peak load reduction., fossil fuel conservation, $\mathrm{CO}_{2}$ emissions, $\mathrm{NO}_{\mathrm{x}}, \mathrm{So}_{\mathrm{x}}$ matter.

\subsection{Material}

The research recommends keeping and increasing their applied solutions in material such as Responsible building materials, construction, demolition of waste, responsible sourcing of materials, insulation, design for durability, material efficiency, hard landscaping and boundary protection. sustainable purchasing, sustainable furniture, sustainable food, non-polluting material, design for flexibility, modular flooring system, design for durability, recycling materials, waste management, regional material, responsible sourcing materials, recycled materials.

The research recommends adopting such solutions as:

Life cycle impact, sustainable products, Life cycle impact, sustainable policy, solid waste policy, reduction mercury lamps, design material reduction, design for disassembly, building reuse, material reuse, regional material, rapidly renewable material, reused certified timber, and improve operation waste management, organic waste management, material reuse, LCA.

\subsection{Indoor Environment}

The research recommends keeping and increasing their applied solutions in material: Indoor air quality, acoustic comfort, lighting comfort, visual comfort, indoor pollutants, and thermal comfort, best management practice, control lighting, daylight view, sustainable cleaning equipment, chemical control, ventilation quality, materials emissions, indoor air quality, thermal zone, views, daylight, noise control, and secure environment.

The research recommends adopting solutions such as:

Environmental tobacco control, green cleaning, occupant comfort, thermal comfort control, and thermal comfort modelling.

- The research strongly recommends applying the common categories shared by the five global systems in the research method of assessment, which, are sustainable site, indoor environment quality, energy efficiency, water efficiency and building material.

- The research recommends adding additional categories like the educational value in learning green star certified professional, LEED certified design, by having workshops or continuous educational courses in specific assessment methods.

- The research recommends adding suitable categories to their local environment. Solutions are not applied for its high expensive solutions like energy-efficient transportation system. It is very important to study their local environmental, special, technological conditions in the local environment in Greater Khartoum and apply economical solutions suitable to local environmental, social and economic value. 
- The case studied added three categories suitable to local environmental, social and economic conditions, detailed by the passive solutions can be applied in their houses, which are; building form, outdoor environment and sustainable design process to add educational value.

\section{Acknowledgement}

I would like to thank Dar Al Uloom University staff and members Specially Deanship for Graduate Student and Research For Funding my research. University of Khartoum staff for continuous help during my PhD research. I would also like to thank my supervisor Prof. Saud Sadiq Hassan for continuous help and Guidance's. My Thankful should be extend to Dr Osman M. ElKheir for his continuous help and Guidance's.

\section{References}

Abdelmoneim, H. (2016). Impact Of Khartoum Refinery Gaseous By-Products on The Environment. Pinnacle Educational Research \& Development Journal, 4(1), 809-818.

Abdelmoneim, H. (2019). Sustainable -Eco- Building -Assessment method to Evaluate Residential Building in Greater Khartoum, $\mathrm{PhD}$ research published with Scholar Press, Germany. Retrieved from https://www.amazon.com/s?k=hind+abdel+moneim+khogali\&ref=nb_sb_noss

Abdelmoneim, H. (2020). Sustainable-Eco -Building Assessment method to Evaluate Residential Building in Greater Khartoum.

Alwetaishi, M. (2018). Toward Sustainable Building Design in Hot and Arid Climate with Reference to Riyadh City, Saudi Arabia. International Journal of Civil and Environmental Engineering, World Academy of Science, 12(5), 572-575. https://doi.org/10.1080/23311916.2018.1452665

Barrows, J. (2009). Strategies for Sustainable Architecture (1st ed.). USA: Taylor \& Francis.

BREEAM. (2014). BREEAM. Retrieved Agust, 2014, from http://www.BREEAM.org

Bromberek, Z. (2009). Eco Resorts Planning and Design for the Tropics (1st ed.). USA: Talyor and Francis. https://doi.org/10.4324/9780080939681

Council, A. D. U. P. (2020b). Abu Dhabi Urban Planning Council. Retrieved Agust, 2019, from http://www.upc.gov.ae/home

Council, U. S. G. B. (2020a). United State Green Building Council. Retrieved Agust, 2019, from http:www.usgbc.org

GSAS. (2014). GSAS. Retrieved Agust, 2019, from http://www.gsas.org

Hyde, R. (2008). Bioclimatic Housing Innovative Design for Warm Climates (1st ed.). USA: Cromwell.

Ibrahim, A. M. (1987). The Arab Architects - Hassan Fathy (1st ed.). Cairo: Center of Planning and Architecture Studies.

Khalil, A. (2014). Review on Developing a Residential Projects Sustainability Assessment Tool for Developing Countries With Focus on Greater Khartoum. Khartoum-Sudan, SEEP -Dubai -UAE.

Kubba, S. (2010). LEED Practices, Certification, and Accreditation Handbook (1st ed.). UK: Elsevier Press. https://doi.org/10.1016/B978-1-85617-691-0.00001-1

RIBA. (2010). RIBA Megazine. Retrieved November 15, 2010, from http://www.RIBA Trust.com

Roaf, S. et al. (2013). Eco Building Guide line (3rd ed.). UK: Architectural Press.

Sassi, P. (2006). Strategies For Sustainable Architecture (1st ed.). USA, Canada: Taylor \& Francis. https://doi.org/10.4324/9780203480106

$\mathrm{Su}$, Y.-M. (2016). Improvement of Ventilation and Thermal Comfort Using the Atrium Design for Traditional Folk Houses-Fujian Earthen Building. Paris, World Academy of Science, Engineering and Technology, IECC.

UN-HABITAT. (2016). Sudan Report For The $3^{\text {rd }}$ International Conference For Housing and Sustainable Urban Development. Khartoum: UN-HABITAT and Minstry of Environment and Forest.

Washington DC, C. F. A. P. (2020). Center for American Progress, Enough Project. Retrieved February, 2020, from http://www.enoughproject.org/conflicts/sudans

Zuhal, A. E. (2018, November). Exploring Sustainability in Providing Low - Cost Housing in Khartoum - Sudan Khartoum, Department of Architecture and Physical Planning, Building and Road Research Institute. 
Retrieved from https://www.researchgate.net/publication/336375363_Sustainable_lowcost_housing_in_Sudan_between_Theory_and_Practice?isFromSharing=1

Zuhal. (2014). The Opportunities and Challenges for Sustainability in Old Neighbourhoods-A Case Study of Aburoof Neighbourhood - Sudan. Journal of Sustainable Development in Africa, 17(6). Retrieved from http://www.jsd-africa.com/Jsda/Vol17No7-Winter15A/article17-07.html

\section{Copyrights}

Copyright for this article is retained by the author(s), with first publication rights granted to the journal.

This is an open-access article distributed under the terms and conditions of the Creative Commons Attribution license (http://creativecommons.org/licenses/by/4.0/). 